\title{
Multi State Farmer Dealer Assistant
}

\author{
Niki Tandel ${ }^{1}$, Machhi Pratha², Patel Krishna ${ }^{3}$, Patil Pinal ${ }^{4}$, Mrs. Arpana Mahajan', \\ Dr. Sheshang Degadwala ${ }^{6}$ \\ ${ }^{1-4 U}$.G.Student, Computer Engineering, Sigma Institute of Engineering, Vadodara, Gujarat, India \\ ${ }^{5}$ Assostant Professor, Computer Engineering, Sigma Institute of Engineering, Bakrol, Gujarat, India \\ ${ }^{6}$ Head of Department, Computer Engineering, Sigma Institute of Engineering
}

\begin{abstract}
A Web venture with Android App to enable agriculturists to guarantee more noteworthy benefit through direct rancher to provider and agriculturist to agriculturist correspondence over various states. This administration supports business correspondence and acquires straightforwardness the framework. This creative site takes into account great agriculturist, retailer and provider correspondence. It enables ranchers to login and refresh the items, cost, and stock with convey to particular merchants. At the point when merchants give arrange rancher get message notice. Additionally, giving Tracking office to the merchants. Furthermore, at whatever point merchant/Farmer distributes a notice or offer, the individual ranchers get advised by means of SMS message. The ranchers may likewise present their grievances and grumblings to particular merchants or experts utilizing their agriculturist login on a different protestations page and specialists will gain admittance to that page frequently utilizing their login id and passwords. Watchwords: Multi State, Farmer, Supplier, Admin, Sell-Buy, Booking.
\end{abstract}

Keywords: Multi State, Farmer, Supplier, Admin, Sell-Buy, Booking.

\section{INTRODUCTION}

In Multi state Farmer Dealer Assistance will be web/Mobile Application Service. This innovative site allows for good farmer, retailer and supplier communication. Allow farmer to login and communicate to respective dealer/end users. When farmer publish offers or advertisement the respective dealer/end users get notified via SMS or Email. This service helps farmers to sell their product easily to the dealers/end users. It provides us information about

district wise production like grain, cereals, oil seeds fruits, vegetables etc.
A web project to help farmers ensure greater profitability through direct farmer to supplier and farmer to farmer communication. This site is simple user interface so rural people can use it. Also Farmer can submit their grievance online.

The increased complexity of the systems inhibits easy adoption and makes calculations as to the financial benefits uncertain. 


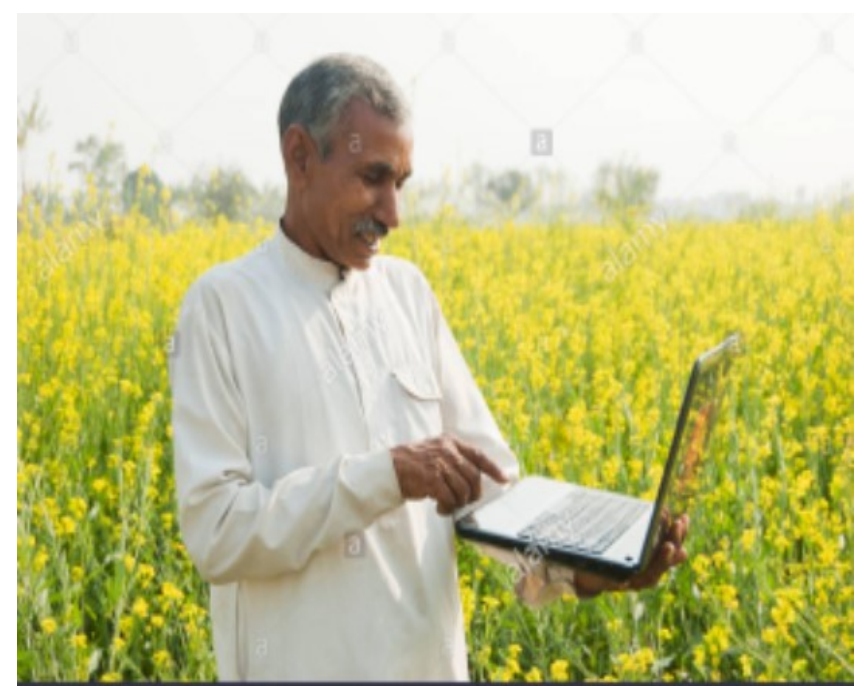

Figure 1: Farmer at Farm

\subsection{Scope of the System}

This system aim to provide reduction as well as increasing of sales. In future we can also add tracking and tracing.

This system provides better productivity improvement and high customer satisfaction. we can provide better control of product safety and quality also transparency of supplier.

\subsection{0bjective}

To integrate technologies and tools to make cost efficient compliance with standards an integral part of farm operations.

To show a better understanding of how farming will develop.

To identify and analyse a range of formal and informal management strategies in crops.

To produce a set of specification that can be used to define a flexible and dynamic farm management information system.

To develop a sustainable system for guaranteed adequate food production in the foreseeable.

To develop an alternative strategies over chemical farming.

To provide notification via Email or SMS.

To help farmer to sell their product easily.

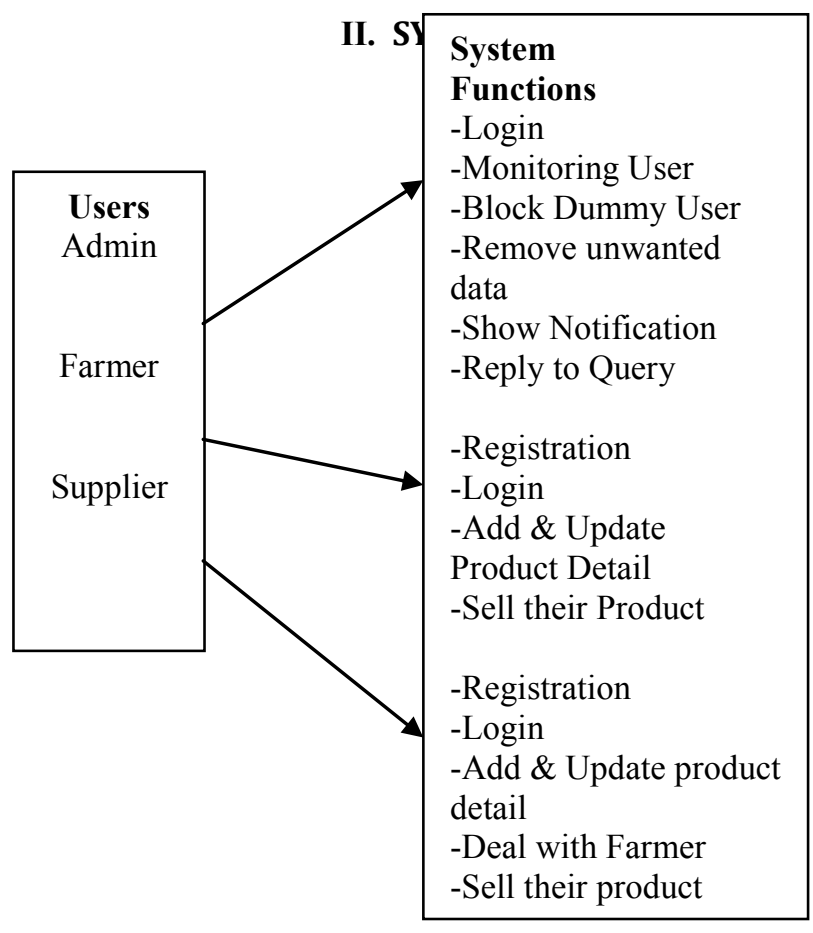

Figure 2: Function of System

A. Farmer: First Farmer can registration for the online system and then login with username and password. The farmer can update the product details $\&$ their price Farmer can update the date and time of the product farmer can deal with Suppliers and Farmer.

B. Supplier: First supplier can registration for the online system and then login with username and password. Supplier can post advertisement by specify the name of the crop he required further this add is send to the respective farmers via SMS. A supplier can deal with Farmer and sell their product. Supplier can view the Update of product by farmer.

C. Admin: Admin can login to the system and monitoring the system. Admin block the Dummy users and also provide the information of farmer and supplier. Admin can view the list of end users who requesting for buying the product. 


\section{Module of the system}

\begin{tabular}{|l|}
\hline Registration \\
\hline Searching product for sell \\
\hline Adding product for sell \\
\hline Tracking \\
\hline Notification \\
\hline Privacy \\
\hline
\end{tabular}

Figure 3: Module of System

A. Registration: All the users like Farmer, Supplier/Dealers will be registration for Application or website.

B. Searching Product for sell: All the Suppliers/Dealers are searching for the product by related Area, Product price, Product Quality, Product Quantity etc.

C. Adding Product for the sell: Farmer and Supplier/Dealer add their product like vegetable, Fruits, Cereals, Oil Seeds by Particular price and product quality and quantity.

D. Tracking: When Farmer sending product to suppliers/Dealers the he enter supplying information into the system and when suppliers/Dealers receive the product he also enter receiving information into the system.

E. Notification: Notification will be provide via Email Address \& SMS.

F. Privacy: Provide privacy can be OTP based password authentication \& Scanning Adhar Card.

\subsection{Weakness of Current System}

In current system, the farmer who are the producers of agriculture goods, may not have their own storage facilities so, absence of storage forces the farmers sell their product in very low prices in the market.
Farmer cannot directly communicate with supplier and end users so lots of product is wastage. The most common problem with the farmer are marketing of their produce and receiving all types of input regularly.

\subsection{Weakness of the System}

This system is only use when internet is available. This system is only use in PC and Smart phone only.

\subsection{Advantages}

Farmer May submit their grievances online.

Help Farmer to sell their product easily.

This site is simple user interface so rural people can use it.

\subsection{Disadvantage}

This site creates competition between two farmer.

\subsection{Myths}

\section{Myth-1: All Farms are large, corporate farms}

The truth-97 percent of all farms are family owned and run. Don't let the names of some fool you, just because they are incorporated does not mean they are a corporation. These families live and work on this land that has, in many cases, been in their family for generation.

\section{Myth-2: Small Farms are not important}

The truth-small farms are the backbone of the agindustry. Small farms allow for people to get locally produced food and maintain a personal relationship with the farmer.

\section{Myth-3:All Farmer are rich}

The truth-farmer don't farm for the money, they do it because they love it. That's not to say that there aren't farmers out there that are rich but a few does not equal a whole. Farmers farm because they love the lifestyle, they know there is no better way raise kids than on a farm or they know it is truly the most important profession out there. Whatever the reason may reason may be, it sure isn't for the money.

\section{Myth-4:Farmer are uneducated}

The truth- not only do they have the job of farming, the must also be mechanics, weathermen, veterians, business men \& women, the marketers, scientists and so much more. Long gone are the days of relying 
on old farm wisdom and hoe people have always done it. Times have changed as have the duties and required knowledge of being a farmer.

\section{Myth-5:There is no future in agriculture}

The truth- the best future is in agriculture. Not only are the numbers of graduates with degrees is an agrealted field growing, so too are the numbers of young farmers getting out on the farms.

\section{RESULTS}

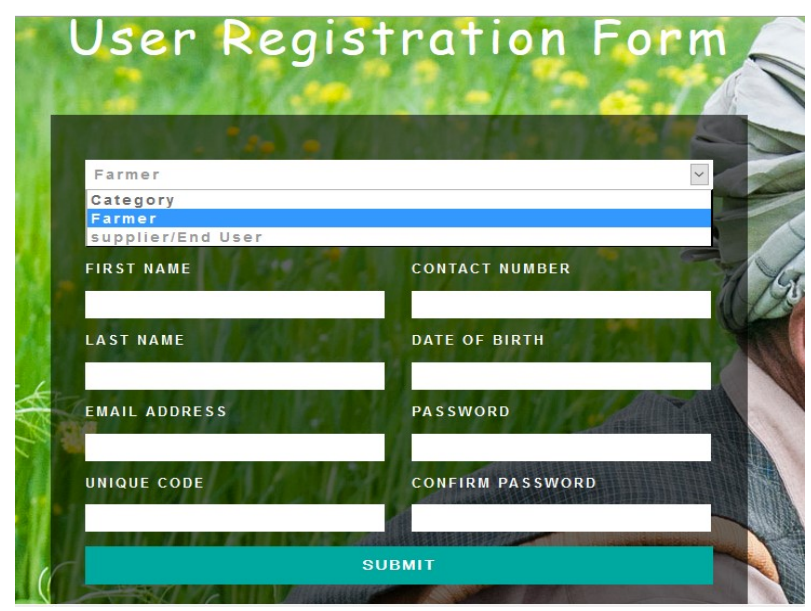

Figure 4: Combine Registration Page form Farmer and Supplier

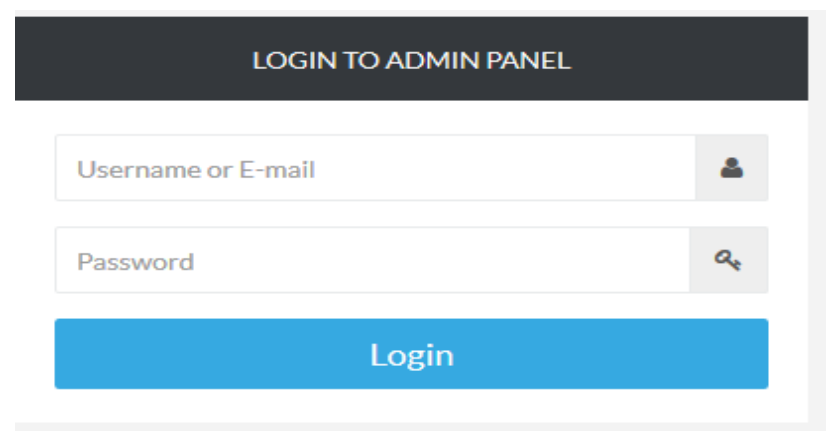

Figure 5: Login Panel for Admin

LOGIN TO FARMER PANEL

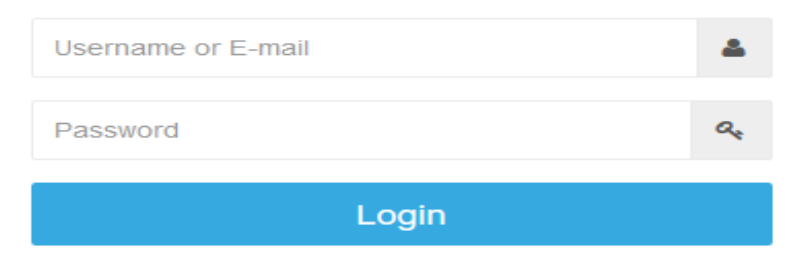

Figure 6: Farmer Login Panel
LOGIN TO SUPPLIER/END USER PANEL

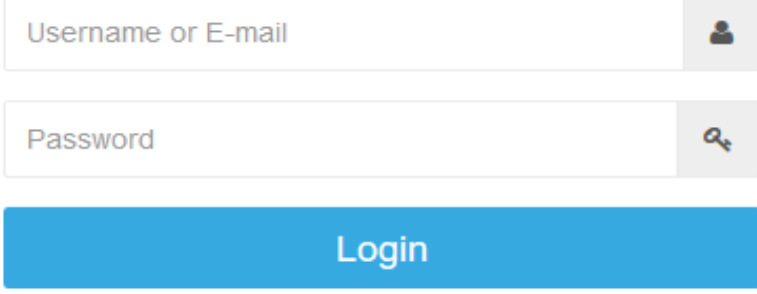

Figure 7: Supplier Login Panel

\section{IV.CONCLUSION}

We have completed our project work based on using software engineering and system analysis and design approach. Work that we have done with preplanning scheduling related with time constrains and result oriented progress in project development. The Resulting Concluding Observations can add considerable weight to online cable management system advocacy. A small report made by us to increase the web interaction and drive to customer for online payment and other facilities available on website

\section{REFERENCES}

[1] Object Oriented Analysis and Design with UML, Author:Michael blaha, Publication:-Pearson, Edition: - 4thRevised Edition

[2] Database System Concepts, Author:- Abraham Silberschat, Henry F. Korth, S.Sudarshan Publication:- McGraw Hill International Publication, Edition:- $6^{\text {th }}$ Edition

[3] Software Engineering:- Theory and Practice by Pearson Education, India

[4] http://www.gtpl.net/high-definition.html

[5] http://www.W3school.com

[6] http://www.dennetworks.com

[7] http://www.templatemonster.com

[8] http://www.indigital.co.in 